\title{
A Novel Reconfiguration Method in Smart Distribution Grid Considering Interval Data and Distributed Generation
}

\author{
W. Dai, W.X. Sheng, K.Y. Liu \\ Department of Power Distribution \\ China Electric Power Research Institute
}

China

\begin{abstract}
This paper investigates optimal network reconfiguration problem considering data uncertainties, with the integration of distributed generation (DG) in distribution grid. The proposed network reconfiguration formulation is formed as a multi-objective optimization problem. Through normalization of each objective function, the multi-objective optimization is transformed to single-objective optimization. The optimization problem is further solved by combining Binary Particle Swarm Optimization (BPSO) and Harmony Search Algorithm (HSA) considering DG integration, where BPSO is utilized to solve the reconfiguration problem, and DG placement is optimized based on the optimal network structure using improved HSA. Interval analysis is applied to deal with parameter uncertainties. Numerical tests on IEEE 33-bus, PG\&E 69-bus show the applicability of the proposed method. The computational result indicates that the proposed algorithm for optimal network reconfiguration is feasible and effective.
\end{abstract}

Keywords-distribution reconfiguration; interval analysis; reliability; data uncertainty

\section{INTRODUCTION}

Many algorithms have been proposed to solve network reconfiguration. Heuristic algorithms were investigated to find optimal network structures in [1]-[3]. A considerable number of intelligent algorithms are also applied into reconfiguration problems in [4]-[6]. To deal with uncertainties in power system, different methods have been proposed. Interval analysis was utilized in [2], and other methods were proposed in [7]-[8]. Some representative methods for DG integration were proposed in [9] [10].

In this paper, we firstly establish the multi-objective network reconfiguration model with the consideration of minimum line loss, minimum Expected Energy Not Supplied (EENS) and minimum switch operation cost, and then the problem is solved by combining Binary Particle Swarm Optimization (BPSO) and HSA considering the DG placement. Further, interval analysis is applied to deal with parameter uncertainties.

\section{PROBLEM FORMULATION}

\section{A. Objective Functions}

1). Formulation of line loss cost. The line loss equation on feeders is described as follows:

\author{
Y. Sheng, Z.J. Ye \\ Shaoxing Electric Utility of State Grid \\ Zhejiang Power Company \\ Zhejiang, China
}

$$
P_{\text {tloss }}=\sum_{k=0}^{N-1} P_{\text {loss }, k \sim(k+1)}, \quad P_{l o s s, k \sim(k+1)}=\frac{R_{k}\left(P_{k}^{2}+Q_{k}^{2}\right)}{\left|U_{k}\right|^{2}}
$$

Then the power loss cost can be expressed as:

$$
f_{1}(x)=P_{\text {tloss }} \tau d
$$

2). Formulation of EENS. The EENS can be quantified as:

$$
f_{2}(x)=\sum_{i=1}^{n} T_{i} P_{a, i}
$$

where $P_{a, i}$ is the average load connected at bus $i$, and $T_{i}$ is defined as Annual Outage Time (AOT)[11]. AOT of bus $i$ can be calculated with equipment parameters as:

$$
T_{i}=\sum_{k=1}^{m} \lambda_{k} \times r_{k}
$$

where $m$ is the total number of equipment at bus $i, \lambda$ and $\gamma$ stand for equipment annual fault rate and average repair time, respectively [12].

3). Formulation of Switch Operation Cost. Marking Operation cost as $q$ per time. Marking operation time as $N_{o p}$, the expression of operation cost should be as:

$$
f_{3}(x)=N_{o p} \times q
$$

\section{B. Constraints}

$$
\begin{aligned}
& \text { 1). Topology Constraint } \\
& g \in G
\end{aligned}
$$

where $g$ is the topology structure after reconfiguration. $G$ represents the set of all feasible topology structures.

2). Equality Constraint. The power flow equation should be satisfied after network reconfiguration, which can be described as follows: 


$$
\left\{\begin{array}{l}
P_{i}-P_{D G, i}=U_{i} \sum_{j=1}^{n} U_{j}\left(G_{i j} \cos \delta_{i j}+B_{i j} \sin \delta_{i j}\right) \\
Q_{i}-Q_{D G, i}=U_{i} \sum_{j=1}^{n} U_{j}\left(G_{i j} \sin \delta_{i j}-B_{i j} \cos \delta_{i j}\right)
\end{array}\right.
$$

3). Inequality Constraints:

$$
\begin{cases}U_{i}^{\min } \leq U_{i} \leq U_{i}^{\max }, & i=1,2, \cdots \cdots, n \\ I_{i} \leq I_{i}^{\max }, & i=1,2, \cdots \cdots, n \\ P_{G, i} \leq P_{G, i}^{\max }, & i=1,2, \cdots \cdots, k\end{cases}
$$

4). Formulation of Target Function. Considering interval analysis, the objective function can be formed as:

$$
\begin{aligned}
& F\left(\left\{x_{i}\right\},\left\{S_{j}\right\}\right)=w_{1}\left(\sum_{i=1}^{n}\left[T_{i}\right] P_{a, i}\right) b+w_{2}\left[P_{\text {toss }}\right] \tau d+w_{3} N_{o p} q \\
& \quad+w_{4} \sum_{i=1}^{N}\left[\frac{\min \left(\underline{U}_{i}-U_{i}^{\min }, U_{i}^{\max }-\bar{U}_{i}, 0\right)}{U_{i}^{\max }-U_{i}^{\min }}\right]^{2}+w_{5} \sum_{i=1}^{N}\left[\frac{\min \left(I_{i}^{\max }-\bar{I}_{i}, 0\right)}{I_{i}^{\max }-I_{i}^{\min }}\right]^{2}
\end{aligned}
$$

\section{PROPOSED DiSTRIBUTION RECONFIGURATION METHOD}

\section{A. Generating Feasible Solution Algorithm Using BPSO}

BPSO is a binary version of PSO algorithm. In this paper, BPSO is utilized to search feasible solutions for network reconfiguration.

The procedure of BPSO can be described as follows:

Step 1) Describe the status of all switches as array $A$ containing only 0 and 1 , which means open and closed status respectively.

Step 2) Generate the adjacent branch matrix and bus incidence matrix of the system. Search for loops formed by closing sectional switches, and save the loops as arrays $\left\{b_{i}\right\}$.

Step 3) Generate particle swarm until the swarm size reaches the requirement.

Step 4) Generate solutions and do topology analysis. Update the best solution.

Step 6) Do Step 5 until the iteration reaches the maximal iteration $t_{\max 1}$, or the required accuracy is satisfied. Output the best index and the topology structure.

\section{B. Topology Analysis}

Topology analysis can detect whether the network generated by BPSO has loops or islands. Since the particle generating process determines that the network must be open loop, the system will not contain any closed loops. For a network generated by BPSO, its bus incidence matrix is marked as $B$. The sum of each row is the grade of each node. The proposed method to find island system is as follows:

1) Calculate grades of all the nodes in node incidence matrix $B$. If the grade of any node is equal to 0 , it represents an island node, which means the network structure is not feasible; 2 ) If there is no island node, delete the maximal node number with grade that equals to 1 , and repeat step 1 ; 3 ) Repeat 1 to 2 until the network has only two nodes.
As the procedure continues, the matrix will finally become a 2-bus system. If the grades of remaining buses are both 1 , which meets the termination condition of the procedure, then it proves that the original network structure doesn't contain any islands.

\section{Interval Analysis Method}

Interval analysis is applied into FBSM in this paper, which is shown as:

$$
\begin{aligned}
& \left\{\begin{array}{l}
{\left[I_{n}^{(k)}\right]=Y\left[U_{n}^{(k)}\right]+f\left(\left[U_{n}^{(k)}\right]\right)} \\
{\left[I_{b}^{(k)}\right]=A^{T}\left[I_{n}^{(k)}\right]}
\end{array}\right. \\
& \left\{\begin{array}{l}
{\left[U_{b}^{(k+1)}\right]=Z\left[I_{b}^{(k)}\right]} \\
{\left[U_{n}^{(k+1)}\right]=\left[U_{n}^{(0)}\right]-A\left[U_{b}^{(k+1)}\right]}
\end{array}\right.
\end{aligned}
$$

In equation (10) and (11), each variable appears only once in every iteration of FBSM, thus keeping the interval calculation not so conservative. As for complexity, the interval FBSM costs only two times than that in traditional FBSM.

\section{Optimal DG Sizing Based on Improved HSA}

HSA can deal with continuous variable with the merit of many stochastic optimization methods [10] [13]. To optimize DG sizing after network reconfiguration, the procedure of applying HSA are as follows:

Step 1) Generate the HSA objective function. Multiple DG capacities are set as independent variable. Step 2) Generate initial harmony vectors. Step 4) Update harmony memory. Step 5) If the iteration reaches the maximum iteration $t_{\max 2}$, output the result.

\section{EXPERIMENTS AND ANALYSIS}

A. Test Case on IEEE 33-Bus System

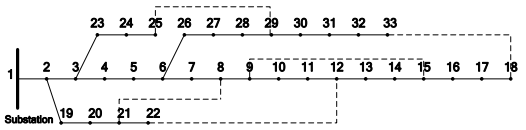

\section{FIGURE I. SCHEMATIC DIAGRAM OF IEEE 33-BUS SYSTEM}

IEEE 33-bus system is a standard $12.66 \mathrm{kV}$ radial distribution network with 33 tie switches and 5 sectional switches. Two DG units with power ranging from 0 to $2 \mathrm{MW}$ are considered to integrate. Reliability parameters are shown in Table 1 , and $10 \%$ variation is included to simulate the interval analysis. Solutions are shown in Table 2 . The voltage profile is shown in Fig. 2. Interval data is shown in brackets.

\section{TABLE I. RELIABILITY DATA OF RELATED EQUIPMENT}

\begin{tabular}{|c|c|}
\hline Items & $\lambda \times r$ (h/year $)$ \\
\hline Overhead lines & $0.325[0.292,0.358]$ \\
\hline Breaker & $0.0464[0.0418,0.0509]$ \\
\hline Switch & $0.04[0.036,0.044]$ \\
\hline
\end{tabular}


TABLE II. THE OPTIMIZATION RESULT OF IEEE-33 BUS SYSTEM

\begin{tabular}{|c|c|c|c|}
\hline \multicolumn{2}{|c|}{ Scenario } & \multirow{2}{*}{\multicolumn{2}{|c|}{$\frac{\text { Parameters (with interval) }}{\{8-21,9-15,12-22,18-33,25-29\}}$}} \\
\hline \multirow{4}{*}{ I } & $\begin{array}{c}\text { Open } \\
\text { Switches }\end{array}$ & & \\
\hline & $\begin{array}{l}\text { Power Loss } \\
(\mathrm{kW})\end{array}$ & 190.99 & {$[108.95,266.06]$} \\
\hline & EENS & 2709.4 & [2438.5,2980.3] \\
\hline & $\begin{array}{l}\text { Minimum } \\
\text { voltage } \\
\text { (p.u.) } \\
\end{array}$ & 0.9141 & {$[0.8719,0.9178]$} \\
\hline \multirow{6}{*}{ II } & $\begin{array}{c}\text { Open } \\
\text { switches }\end{array}$ & \multicolumn{2}{|c|}{$7-8,9-10,14-15,25-29,32-33$} \\
\hline & $\begin{array}{c}\text { Power loss } \\
(\mathrm{kW})\end{array}$ & $129.83(32.02 \%)$ & {$[75.41,161.33]$} \\
\hline & EENS & $2694.5(0.6 \%)$ & {$[2425.1,2964.5]$} \\
\hline & $\begin{array}{l}\text { Minimum } \\
\text { Voltage } \\
\text { (p.u.) }\end{array}$ & 0.9388 & {$[0.9292,0.9536]$} \\
\hline & $\begin{array}{c}\text { Operation } \\
\text { number }\end{array}$ & \multicolumn{2}{|c|}{4} \\
\hline & $\begin{array}{l}\text { Calculation } \\
\text { time (s) } \\
\end{array}$ & 16.54 & 21.95 \\
\hline \multirow{6}{*}{ III } & $\begin{array}{c}\text { Open } \\
\text { switches }\end{array}$ & \multicolumn{2}{|c|}{$8-21,9-15,12-22,18-33,25-29$} \\
\hline & $\begin{array}{l}\text { DG Output } \\
\& \text { locations }\end{array}$ & \multicolumn{2}{|c|}{$\begin{array}{l}0.2364(32) \\
1.1652(31)\end{array}$} \\
\hline & $\begin{array}{c}\begin{array}{c}\text { Power Loss } \\
(\mathrm{kW})\end{array} \\
\end{array}$ & \multicolumn{2}{|c|}{$68.54(64.11 \%)$} \\
\hline & EENS & \multicolumn{2}{|c|}{2709.4} \\
\hline & $\begin{array}{l}\text { Minimum } \\
\text { voltage } \\
\text { (p.u.) }\end{array}$ & \multicolumn{2}{|c|}{0.9438} \\
\hline & $\begin{array}{l}\text { Calculation } \\
\text { time }(\mathrm{s})\end{array}$ & \multicolumn{2}{|c|}{16.33} \\
\hline \multirow{7}{*}{ IV } & $\begin{array}{l}\text { Open } \\
\text { switches }\end{array}$ & \multicolumn{2}{|c|}{$7-8,9-10,14-15,25-29,32-33$} \\
\hline & $\begin{array}{l}\text { DG output } \\
\& \text { locations }\end{array}$ & \multicolumn{2}{|c|}{$\begin{array}{l}0.1511(32) \\
0.9057(31)\end{array}$} \\
\hline & $\begin{array}{c}\text { Power Loss } \\
(\mathrm{kW})\end{array}$ & \multicolumn{2}{|c|}{$63.80(66.60 \%)$} \\
\hline & EENS & \multicolumn{2}{|c|}{$2694.5(0.6 \%)$} \\
\hline & $\begin{array}{l}\text { Minimum } \\
\text { voltage } \\
\text { (p.u.) } \\
\end{array}$ & \multicolumn{2}{|c|}{0.9482} \\
\hline & $\begin{array}{c}\text { Operation } \\
\text { number }\end{array}$ & \multicolumn{2}{|c|}{4} \\
\hline & $\begin{array}{l}\text { Calculation } \\
\text { time }(\mathrm{s})\end{array}$ & \multicolumn{2}{|c|}{30.08} \\
\hline
\end{tabular}

As shown in Table 2, the improvement in scenario IV proves to be more significant than in II and III. The EENS is reduced from 2709.4 to 2694.5 , and it's mainly influenced by network reconfiguration, which can explain why EENS keeps the same in scenario II and IV. Nevertheless, the minimum voltage of the system is also improved in scenario IV.

It can be seen that DG installation after reconfiguration is proved to be effective than simply applying one of them into system. As shown in Fig. 2, DG installation significantly improves the voltage profile in scenario III, and even better in scenario IV when combined with reconfiguration.



FIGURE II. VOLTAGE PROFILES OF IEEE 33-BUS SYSTEM

\section{CONCLUSIONS}

To summarize the modeling, optimization algorithm and comparison study for distribution network reconfiguration considering data uncertainties, the following conclusions can be derived as: 1) A multi-objective reconfiguration planning model is proposed in this paper. The multi-objective considerations include power loss, EENS, switching operations, DG placement, etc. 2) Interval analysis is utilized in BPSO, making it possible to deal with uncertainties in reconfiguration problems including equipment reliability, seasoning changes, etc. 3) An effective topology analysis method is proposed for open loop system. Different from traditional methods, the proposed method makes use of open loop rules, thus skipping loop detecting part and focusing on detecting islands.

\section{REFERENCES}

[1] A. Gonzalez, F. M. Echavarren, L. Rouco, et al., "A sensitivities computation method for reconfiguration of radial networks," IEEE Trans. Power Syst., vol. 27, no. 3, pp. 1294-1301, 2012.

[2] P. Zhang, W. Y. Li, S. X. Wang, "Reliability-oriented distribution network reconfiguration considering uncertainties of data by interval analysis," Int. J. of Electr. Power Energy Syst., vol. 34, no. 1, pp. 138$144,2012$.

[3] T. L. N. Rugthaicharoenchep, "Network reconfiguration for load balancing in distribution system with distributed generation and capacitor placement," Journal of Energy and Power Engineering, vol. 7 , no. 8, pp. 1562-1570, 2013.

[4] J. Mendoza, R. Lopez, D. Morales, et al., "Minimal loss reconfiguration using genetic algorithms with restricted population and addressed operators: real application," IEEE Trans. Power Syst., vol. 21, no. 2, pp. 948-954, 2006.

[5] B. Enacheanu, B. Raison, R. Caire, et al., "Radial network reconfiguration using genetic algorithm based on the matroid theory," IEEE Trans. Power Syst., vol. 23, no. 1, pp. 186-195, 2008.

[6] C. F. Chang, "Reconfiguration and capacitor placement for loss reduction of distribution systems by ant colony search algorithm," IEEE Trans. Power Syst., vol. 23, no. 4, pp. 1747-1755, 2008.

[7] A. Vaccaro, C. A. Canizares, K. Bhattacharya, "A Range arithmeticbased optimization model for power flow analysis under interval uncertainty," IEEE Trans. Power Syst., vol. 28, no. 2, pp. 1179-1186, 2013.

[8] C. Rakpenthai, S. Uatrongjit, S. Premrudeepreechacharn, "State estimation of power system considering network parameter uncertainty based on parametric interval linear systems," IEEE Trans. Power Syst., vol. 27, no. 1, pp. 305-313, 2012.

[9] P. Pavani, S. N. Singh, "Reconfiguration of radial distribution networks with distributed generation for reliability improvement and loss minimization," Power and Energy Society General Meeting (PES GM), 2013 IEEE, Vancouver, BC, 21-25 July 2013. 
[10] R. S. Rao, K. Ravindra, K. Satish, et al., "Power loss minimization in distribution system using network reconfiguration in the presence of distributed generation," IEEE Trans. Power Syst., vol. 28, no. 1, pp. 317-325, 2013.

[11] R. A. R. Billinton, "Reliability evaluation of power systems," Plenum Press, 1996.

[12] P. Zhang, W. Y. Li, "Boundary analysis of distribution reliability and economic assessment," IEEE Trans. Power Syst., vol. 25, no. 2, pp. 714-721, 2010.

[13] K. S. Lee, Z. W. Geem, "A new meta-heuristic algorithm for continuous engineering optimization: harmony search theory and practice," Computer Methods in Applied Mechanics and Engineering, vol. 194, no. 36-38, pp. 3902-3933, 2005. 